International Journal of Social Science And Human Research

ISSN(print): 2644-0679, ISSN(online): 2644-0695

Volume 05 Issue 01 January 2022

DOI: 10.47191/ijsshr/v5-i1-35, Impact factor-5.586

Page No: 271-275

\title{
Strengthening Women Empowerment and Gender Equality in India
}

\author{
Dr. Parin Somani \\ Independent Academic Scholar
}

\begin{abstract}
Gender equality is a fundamental human right of each person in society and forms a vital foundation for a peaceful and sustainable world. This study aims to understand gender inequalities in India, with the objective of facilitating societies towards sustainable equality. There is an endeavour to strengthen women empowerment through recommended strategies that can be implemented in societies globally. A systematic literature review is carried out via a thorough literature search. Results have indicated that although there has been progression over the last few years including more females acquiring education through attending schools, less forced and early marriages, more females being appointed in leadership positions, there is still a requirement to eradicate gender inequalities further. Challenges highlighted within India include social norms and cultural biases, violence, education, and underrepresentation of women in positions of power. This study has deduced that there is a need for societal education on the identification of women inequality and changes of behaviour in supressed women. Utilisation of technology to promote women empowerment initiatives and collaborate with governmental and non-governmental organisations will facilitate women empowerment, because it is only by working together that gender inequalities can be eradicated.
\end{abstract}

KEYWORDS: Women empowerment, Gender inequality, India, Covid-19

\section{INTRODUCTION}

Contemporary life is subject to continuous change particularly residing in the technological era, where there is rapid globalization and technological advancements are at a peak (Somani, 2021). Gender equality is a fundamental human right of each person in society and forms a vital foundation for a peaceful and sustainable world, however, despite numerous advancements gender inequality is still present (Belingheri, Chiarello, Fronzetti Colladon, \& Rovelli, 2021). Historically in the early 1800's, a woman's role was predominantly to perform domestic duties in the home environment. They had been defined as keepers of the home and homebased ethical teachers imparting ethics to their families and within society. Simultaneously they were housewives who resumed the role of giving birth to children, looking after the family, and succumbing to their husbands (Cerrato \& Cifre, 2018). Within social settings, women were deemed as the weaker sex, thus inadequate compared to males resulting in gender inequalities. Within contemporary life the way women were treated in history can be perceived as conditions comparable to slavery because women did not control their own lives, instead they were dominated by men within society (Nan \& Chang, 2019). This stemmed from male parents prior to marriage, thereafter the women's husband. The implementation of women movements became very effective; therefore, women began to challenge the social, traditional, economical, and political systems that had caused injustice for a long time, which initiated their new roles in society. Nevertheless, women have previously been exposed to reduced occupational opportunities and legal rights because of underrepresentation compared to males because a women's professional priority was deemed motherhood and wifehood. With the progression of time women won voting rights towards the end of nineteenth century (Teele, 2020). Women have also increased their chances to access education and other professions which were deemed for men only.

The stability of society was based upon a sound foundation involving the sanctity of marriage (Pessin, 2018). Within this partnership there was an expectation for women to obey their husbands and agree with them to ensure a stable and happy marriage. However, there were some topics that caused disputes, one of which was women's right to education, consequently leading to protests (Cain \& Dier, 2020). It was only the daughters of wealthy parents that were able to acquire formal education for a large monetary value situated within their home environments. However, a well-educated female was perceived as unattractive to a male suitor thus attaining a marriage proposal became more difficult. Therefore, even within education the accessibility to learn subjects was limited and including reading, writing and languages. In addition, subjects available were directed at training women to be good homemakers and the subjects were deemed to help reach excellence in their 'wifely responsibilities' including knitting, midwifery, cooking and weaving (Whittle \& Hailwood, 2020). It was the formation of "women rights movements" which facilitated protests to 


\section{Strengthening Women Empowerment and Gender Equality in India}

stop slavery and men dictatorships. This led to revolution and ultimately the constitutional amendment processes and eradicating slavery. Women were able to view their opinions without oppression hence constituting towards a great achievement for women in history.

In contemporary life, women have become resistant to male oppression in numerous countries globally and they aim to become completely independent of their male counterparts. Women have earnt their rights through persistence and protests demanding equal education opportunities and religion activism overcoming oppressing challenges that were imparted by males and even opposing females in the past. Eventually, women commenced to seek employment outside their homes and imparted their knowledge and skills within socially accepted job roles. Although society have progressed revealing more opportunities for women, there are still many disparities between men and women that need to be addressed.

\section{Objectives}

This study aims to understand gender inequalities in India, with the objective of facilitate societies towards sustainable equality. There is an endeavour to strengthen women empowerment through recommended strategies that can be implemented in societies globally.

\section{METHODOLOGY}

This study is carried out by means of a systematic literature review via a thorough literature search. Manual and electronic databases are utilised which include, books, journals, and magazines. A well-planned process is implemented to search, identify, extract from, analyse, evaluated, and interpret from existing published white and grey literature sources. The following electronic databases are searched: PubMed, JSTOR, Scopus and Google Scholar. The following keywords have been used: 'Women' 'Gender' Inequality' 'India' 'Education' 'History' 'Marriage' 'Culture' 'Gender discrimination'. Numerous literature sources are identified therefore the following exclusion criteria is devised:

- Literature irrelevant to gender inequality in India are excluded

- Literature focusing entirely on women in history are not included

- Literature using languages other than English are ignore

- Literature with information duplicated in newer literature sources are not used

- Literature with insufficient technical information to their approach are excluded

In total of twenty-eight papers are shortlisted to aid focus to this study. Upon closely examining the papers, one was duplicated therefore not used and after reading the abstracts and introductions one was eliminated. This has equated to twenty-six studies. Another literature source was eliminated due to implementation details. Thus, twenty-five literature sources have reached the overall criteria and have been included within this study.

\section{RESULTS AND DISCUSSION}

Results have indicated that although there has been progression over the last few years including more females acquiring education through attending schools, less forced and early marriages, more females being appointed in leadership positions and serving within parliament or governing bodies; there is still a requirement to advance gender equality further. Challenges highlighted within India include education, violence, social norms and cultural biases and the underrepresentation of women in positions of power.

\section{Education}

The United Nations fourth and fifth sustainable development goal is quality education and gender equality (UN, 2022) as disparities are still evident within these areas globally. All females have a right to education in contemporary life however, within India, individuals belonging to lower socio-economic backgrounds are restricted by financial resources and cultural perceptions. This has become particularly evident during the covid-19 pandemic as restricted internet connectivity, access to appropriate hardware and software have become essential. For students that are unable to access essential elements to continue education from remote locations, then numerous students have ceased their education or differed a year (Somani, COVID-19 Lockdown Impact On Education, 2021). Similarly, a higher proportion of females that marry during their educational process are highly likely to discontinue education, instead they become home-makers and bare children (Khurana, 2021). When families are provided with the choice of educating one child due to a lack of finances, they opt to educate the male child in comparison to the female in many Indian families, largely due to systemic subordination where preference is given to males prior to birth. This results from profoundly ingrained systems of patriarchy, reduced female teacher and sanitation facilities like access to toilets which promote preference to males acquiring education. Gradually, societies are starting to understand that by empowering one woman to acquire education, an entire family becomes educated and through her future generations also benefit. This highlights the importance of educating women in society.

\section{India and equality}

In India the Prime Minister Narendra Modi signed the Sustainable Development Goals (SDG) in 2015 after winning the confidence of the $\mathrm{UN}$ as the Asian leader. He has been successfully progressing societies and quoted "Much of India's development agenda is mirrored in the Sustainable Development Goals. Our national plans are ambitious and purposeful; Sustainable development of one-sixth of 


\section{Strengthening Women Empowerment and Gender Equality in India}

humanity will be of great consequence to the world and our beautiful planet" (Modi, 2017). India is the second most populous country in the world after China, and it has the most rapid growing global economy. PM Modi has situated India in a unique position enabling the delivery of what has been committed, pertaining to sustainable development and inclusivity. Through his leadership, India has been pivotal in shaping the SDGs and ensuring balance between the economy, social standings, and the environment. Challenges resulting from financial implications in India is continuously aiming to be overcome by PM Modi as he is committed to changing attitudes working to achieve ambitious goals which include universal rural electrification, road and digital connectivity, expanding clean and renewable energy, good sanitation and housing and universal elementary school education. Reaching goals is attainable with a good supporting team as PM Modi refers to as Sabka Saath, Sabka Vikas defined as a collective effort, inclusive development. Therefore, PM Modi is ensuring collaboration between a diverse range of stakeholders who share their knowledge and skills for the future development of the country and attaining SDGs. Two levels of government are working together to create change. The central government is supporting employment schemes, providing education, building roads between cities and villages and building houses creating opportunities for women from lower socio-economic backgrounds to have the same chances as the men.

Simultaneously, several Chief Minister sub-groups are providing invaluable advice on skill development, digital payments, and implementation of the Clean India Campaign Swachh Bharat Abhiyaan. Due to the rapid progression of the SDGs illustrated within India, it is expected that by the end of 2024 India will be totally cashless due to the establishment of a complete digital economy part of circular economy. It is also estimated that by the end of 2027 all students will be following a single curriculum within schools globally, ensuring that there is access to education for all an initiative commenced by UP UN. This ensures that even students residing in remote villages will have the same quality standard of education as overseas students, despite of gender.

Shri PM Modi has transformed tribalism to globalism creating a solid foundation for sustainable growth and positively impacting future generations. Hence, it is vital for societies to work together to ensure achievements of SDGs we can do this individually, locally, nationally, and internationally. Through this information, individuals are inspired to aid this initiative, act as role models, and facilitate the world towards gender equality and sustainability.

\section{Violence}

Gender equality according to the Indian constitution is a women's basic right and it has a vision of "Empowered women living with dignity and contributing as equal partners in development in an environment free from violence and discrimination. And, well nurtured children with full opportunities for growth and development in a safe and protective environment" (WCD, 2021). Violence against women persists at unacceptably high levels and has been intensified by the covid-19 pandemic. One in three women worldwide, 736 million women even before the pandemic, have experience physical or sexual violence at least once in their life lime from the age of 15 years old, mostly by an intimate partner. Violence against women and girls is a human rights violation (WHO, 2021). During the pandemic, data and reports from front line workers have shown that different types of violence against women and girls, particularly domestic violence, has intensified (Women, 2022). Up to 10million girls will be at risk of child marriage over the next decade because of covid-19 This is in addition to the 100 million that were projected to become child brides before the pandemic (Unicef, 2021).

The pandemic has also added to the increase in the amount of unpaid domestic and care work that women are having to undertake (Seedat \& Rondon, 2021) impacting upon employment levels, mental health, and ability to cope. Women already spend approximately two and a half times as many hours as men on unpaid and domestic and care work. In addition, increasing numbers of female harassment and violence against women persists on streets and public places and within homes. Particularly during the covid-19 pandemic as individuals have implemented government lockdown regulations and self-isolation, there has been an increase in alcohol/ drugs consumption as individuals face insecurity and instability (Mittal \& Singh, 2020). The alarming increase in the number of covid-19 cases and associated effects resulting in death has created a global heath burden on global health services including in India where societies were severely challenges with the number of hospital beds, oxygen cylinders available (Singh, Haldar, Kannaujia, \& Agarwal, 2021). As a result, daily essential services, like domestic violence shelters and helplines, have reached capacity with little or no help or support available.

\section{Social norms and cultural biases}

The role of stereotypes reinforced by social and cultural norms emphasize their vision on gender expectations. Decades of research has shown that stereotyping men and women have a huge impact on our beliefs about how they should or should not behave (Koenig, 2018). Consequently, gender stereotypes reinforce social status and gender hierarchies: for example, surveys and experiments show that women are generally perceived as more "communal" and "loyal", whereas men are described more as "protectors" and "competent" (Player, 2013). Not all individuals subscribe to these stereotypes, however evidence suggests that men and women behave in ways that contradict these traditional stereotypes. For example, negative stereotyping is encountered within societies when a male stays at home and a woman goes to work in India. This is because societies have been conditioned towards expectations and gender specific roles during their lives. They represent and reinforcing unconscious and unseen biases. This notion has also been dramatized within film production in the endeavor to raise societal awareness in India towards important issues, for example 


\section{Strengthening Women Empowerment and Gender Equality in India}

in the Bollywood movie Ki\&Ka starring Karena Kapoor and Arjun Kapoor. In modern day India it is becoming increasingly difficult to successfully balance employment and family life due to competing demands of work and family life. This has created a negative impact on the mental health of women due to increased stress levels (Somani, The Impact of COVID-19 on Human Psychology, 2020). There is a substantial body of research connecting stress to cardiovascular disease, the future manifestation of hypertension related to the individual 's response to stress, metabolic syndrome, obesity, emotional overeating, while stress fuels approximately $50 \%$ of depression cases making it more important to ensure women are supported and gender inequalities are demolished.

\section{Underrepresentation of women in positions of power}

There are multiple elements associated with diversity in the workforce as it constitutes towards creating "vibrant cultures, improved responsiveness to employee and customer needs, greater innovation and creativity, and helps organisations compete in an increasingly globalised (and thus diverse) marketplace" (IES, 2022). Although there has progressively been a reduction in the gender differences, women are still underrepresented in position of power due to the differences in the gender pay gap and habitual mindset within male dominated senior management positions. This can be overcome through every organisation ensuring the implementation of equal pay audits, reformed pay structures, the identification and rectification of unfair pay with the application of pay progression filling in the gender pay gaps, accepting and offering women positions of power in India. For example women are still under-represented in political leadership roles according to the United Nations it will take one hundred and thirty years until gender equality is reached within positions of power, there were only twenty-six women over twenty-four countries that served as Heads of State of Government, as of September 2021 (UN, Facts and figures: Women's leadership and political participation, 2021). It has also been highlighted that during the covid-19 pandemic, women have been largely affected, their resourcefulness and implementation of ideas will enable the recovery of communities globally. Hence, it is believed that by situating women within positions of powers, men and women can work together to plan and make decisions towards a fast recovery.

\section{CONCLUSION}

This study had deduced that gender inequality exists within India and societies internationally. However, it is particularly noticeable amongst the underprivileged belonging to lower socio-economic backgrounds where there is still a reluctance to view women equal to men. Historical social and cultural norms have created a foundation that have become habitual with a reluctance to change. As a result, men still have higher privileges compared to women within India that is noticeable within education, violence, and exploitation, forced marriages and also genital mutation needs to be stopped by shifting cultural beliefs. The covid-19 pandemic has increased the amount of unpaid care and domestic responsibilities placed upon women. This should be a shared responsibility between members of the household regardless of gender. There is a need for more women in leadership roles so that they can be part of the decision-making process, key in devising new laws and developments to progress societies ensuring legislations and policies can be adapted and strengthened. Simultaneously, women need to have equal rights to financial services, economic resources, and property ownership. The UN has five priorities that will help to mitigate the impact of covid-19 on women and hopefully in turn eradicate prejudice. There must be a reduction in Gender-based violence, including domestic violence.; A framework to support females by providing social protection and economic stimulus; The support and practise equal sharing of care work; The involvement of females leading and participating in response planning and decision-making processes; Data and coordination mechanisms including both gender perspectives (UN, Goal 5: Achieve gender equality and empower all women and girls, 2022). There is a need for more feminists who believe in social, political, and economic equality between men and women. The rights to equal opportunities, intellectually and socially with equal recognition and treatment is still a challenge within India.

\section{Recommendations}

Women in societies not only in India, but around the world have been challenged substantially over the decades and during the covid-19 pandemic. Although gender inequalities are gradually subsiding, many factors still require focus as existing gender barriers have been exacerbated. For example: occupational gender stereotyping, bullying, sexual harassment, domestic violence, and equal access to education. It is necessary to raise societal awareness on gender inequalities and utilizing technology to promote women empowerment initiatives. Interactive videoconferencing software, the use of mobile applications and local support groups can be organized. This will enable women to generate a sense of belonging and identity, feel inspired and cultivate the courage and motivation to help themselves and others. It is necessary to educate and support women in society simultaneously raising awareness to other genders identifying behavioural changes in women due to suppression and understand their consequences. Additionally, knowledge on how to approach situations with confidence and collaborate with governmental and non-governmental organisations to facilitate this endeavor because it is only by working together that gender inequalities can be eradicated.

\section{REFERENCES}

1) Belingheri, P., Chiarello, F., Fronzetti Colladon, A., \& Rovelli, P. (2021). Twenty years of gender equality research: A scoping review based on a new semantic indicator. PloS one. 


\section{Strengthening Women Empowerment and Gender Equality in India}

2) Cain, T., \& Dier, R. (2020). Protests and Pushback: Women's Rights, Student Activism, and Institutional Response in the Deep South. History of Education Quarterly , 546-580.

3) Cerrato, J., \& Cifre, E. (2018). Gender Inequality in Household Chores and Work-Family Conflict. Frontiers in psychology.

4) IES. (2022). Equality and diversity. Brighton: Institute for employent studies.

5) Khurana, N. (2021, 03 08). Delivering On The Promise Of Gender Equity In India: Lessons From The UDAYA Study. Retrieved from Health Affairs: https://www.healthaffairs.org/do/10.1377/forefront.20210304.915291/full/

6) Koenig, A. M. (2018). Comparing Prescriptive and Descriptive Gender Stereotypes About Children, Adults, and the Elderly . Frontiers in Psychology.

7) Mittal, S., \& Singh, T. (2020). Gender-Based Violence During COVID-19 Pandemic: A Mini-Review. Frontiers in Global Women's Health.

8) Modi, N. (2017). Voluntary national review report India. New York: United Nations.

9) Nan, Z., \& Chang, L. (2019). Evolved but Not Fixed: A Life History Account of Gender Roles and Gender Inequality. Frontiers in Psychology.

10) Pessin, L. (2018). Changing Gender Norms and Marriage Dynamics in the United States. Journal of marriage and the family, 25-41.

11) Player, A. (2013, 12 06). Gender equality: why women are still held back. Retrieved from The Guardian: https://www.theguardian.com/business/economics-blog/2013/dec/06/gender-equality-women-stereotypes-stop-progress

12) Seedat, S., \& Rondon, M. (2021). Women's wellbeing and the burden of unpaid work. BMJ.

13) Singh, D., Haldar, R., Kannaujia, A. K., \& Agarwal, A. (2021). Desperate times call for desperate measures: An innovative apparatus designed for domiciliary oxygen delivery. Indian Journal of Anaesthesia, 179-180.

14) Somani, P. (2020). The Impact of COVID-19 on Human Psychology. In B. S. Lal, \& N. Patel, Economics of Covid-19 Digital Health Education \& Psychology (pp. 328-357). New Delhi: Adhyayan Publishers \& Distributors.

15) Somani, P. (2021). COVID-19 Lockdown Impact on Education. In P. Somani, P. Sisodia, \& L. N. Jayanthi, Lockdown Impacts (pp. 1-10). Tamilnadu: ESN Publications.

16) Somani, P. (2021). The Role of Education During and After COVID-19. The Journal of Social Sciences Studies and Research, 34-40.

17) Teele, D. L. (2020). Women \& the Vote. Daedalus, 25-39.

18) UN. (2021, 09 15). Facts and figures: Women's leadership and political participation. Retrieved from UN Women: https://www.unwomen.org/en/what-we-do/leadership-and-political-participation/facts-and-figures\#_edn1

19) UN. (2022). Goal 5: Achieve gender equality and empower all women and girls. Geneva: United Nations.

20) UN. (2022). THE 17 GOALS. Geneva: United Nations.

21) Unicef. (2021, 03 07). 10 million additional girls at risk of child marriage due to COVID-19. Retrieved from Unicef: https://www.unicef.org/press-releases/10-million-additional-girls-risk-child-marriage-due-covid-19

22) WCD. (2021, 07 16). Ministry of women and child development. Retrieved from Government of India: https://wcd.nic.in/about-us/about-ministry

23) Whittle, J., \& Hailwood, M. (2020). The gender division of labour in early modern England. Economic History Review, 3-32.

24) WHO. (2021, 03 09). Devastatingly pervasive: 1 in 3 women globally experience violence. Retrieved from World health organization: https://www.who.int/news/item/09-03-2021-devastatingly-pervasive-1-in-3-women-globally-experienceviolence

25) Women, U. (2022, 01 7). The Shadow Pandemic: Violence against women during COVID-19. Retrieved from UN Women: https://www.unwomen.org/en/news/in-focus/in-focus-gender-equality-in-covid-19-response/violence-against-womenduring-covid-19 